\title{
Altered Glucocorticoid Rhythm Attenuates the Ability of a Chronic SSRI to Elevate Forebrain 5-HT: Implications for the Treatment of Depression
}

\author{
SE Gartside*,', MM Leitch' and AH Young' \\ 'Psychobiology Research Group, School of Neurology, Neurobiology and Psychiatry, University of Newcastle upon Tyne, The Medical School, \\ Newcastle, UK
}

\begin{abstract}
Both glucocorticoids and selective serotonin reuptake inhibitors (SSRIs) alter aspects of 5-HT function including somatodendritic 5-HT IA autoreceptor sensitivity. Many depressed patients prescribed SSRIs have pre-existing flattened diurnal gluococorticoid rhythm. In these patients, interactions between flattened glucocorticoid rhythm and chronic SSRIs, which impact on the SSRI's ability to elevate forebrain 5-HT, may alter clinical efficacy. To address this issue rats underwent implantation of slow-release corticosterone (75 mg pellet s.c.) (to flatten the glucocorticoid rhythm) or sham surgery, and injection of fluoxetine ( $10 \mathrm{mg} / \mathrm{kg} /$ day i.p., 12 days) or vehicle. Using microdialysis in the frontal cortex we found that (2I h after the last injection) extracellular 5- $\mathrm{HT}$ was elevated in fluoxetine- or corticosterone-treated animals, but not in those treated with corticosterone plus fluoxetine. In fluoxetine-treated animals, blockade of terminal reuptake by local perfusion of fluoxetine increased 5-HT to the same level as it did in controls, suggesting normal terminal 5-HT release after chronic fluoxetine. However, 5-HT levels following local reuptake blockade in both the corticosterone and corticosterone plus fluoxetine groups were lower than controls, suggesting a corticosterone-induced decrease in terminal release. Finally in fluoxetine, corticosterone, and corticosterone plus fluoxetine groups, there was marked 5- $\mathrm{HT}_{1 \mathrm{~A}}$ receptor desensitization, evidenced by attenuation of the decrease in 5-HT release following systemic fluoxetine injection. The data indicate that, despite desensitization of 5-HT IA autoreceptors, concurrent flattened glucocorticoid rhythm compromises the ability of SSRIs to elevate forebrain 5-HT. These findings suggest a potential mechanism for the reduced antidepressant efficacy of SSRIs in those patients with pre-existing glucocorticoid abnormalities.
\end{abstract}

Neuropsychopharmacology (2003) 28, I572-1578, advance online publication, I4 May 2003; doi:I0.1038/sj.npp. I 30020 I

Keywords: antidepressant; glucocorticoid; selective serotonin reuptake inhibitor (SSRI); serotonin, 5-hydroxytryptamine (5-HT); in vivo microdialysis; 5- $\mathrm{HT}_{\text {IA }}$ autoreceptor

\section{INTRODUCTION}

An increase in synaptic levels of 5-HT in the forebrain may be necessary for the therapeutic efficacy of antidepressant drugs including selective serotonin reuptake inhibitors (SSRIs) (see Blier, 2001). However, pharmacological studies indicate that SSRIs acutely inhibit $5-\mathrm{HT}$ release by increasing activation of somatodendritic 5- $\mathrm{HT}_{1 \mathrm{~A}}$ autoreceptors in the dorsal raphe nucleus (DRN), and this effect limits their ability to increase synaptic 5-HT in the forebrain (Gartside et al, 1995; Hjorth and Auerbach, 1996). On

\footnotetext{
*Correspondence: Dr SE Gartside, Psychobiology Research Group, School of Neurology, Neurobiology and Psychiatry, University of Newcastle upon Tyne, The Medical School, Framlington Place, Newcastle, NE2 4HH, UK, Tel: +44 19I 222 7633, Fax: + 44 191 222 5227, E-mail: sasha.gartside@ncl.ac.uk

Received II October 2003; revised 14 January 2003; accepted 28 February 2003

Online publication: 27 March 2003 at http://www.acnp.org/citations/ Npp032703379/default.pdf
}

chronic administration, SSRIs have been shown to desensitize 5- $\mathrm{HT}_{1 \mathrm{~A}}$ autoreceptors (De Montigny et al, 1990; Le Poul et al, 1995; Davidson and Stamford, 1998). This desensitization, which allows levels of synaptic 5-HT in the forebrain to rise (Gardier et al, 1996; Dawson et al, 2000), shows some temporal correspondence with the onset of antidepressant efficacy (Gardier et al, 1996; Le Poul et al, 1995) and hence is accepted to be an important feature of the response to chronic administration of SSRIs (see Blier et al, 1987, Blier, 2001; Artigas et al, 2001).

Somatodendritic 5- $\mathrm{HT}_{1 \mathrm{~A}}$ autoreceptors are subject to regulation, not only by chronic SSRI administration but also by glucocorticoids (cortisol in man and corticosterone in rodents) (Young et al, 1994; Laaris et al, 1997). This may be of particular importance since, in addition to abnormalities of 5-HT function (Drevets et al, 2000; Sargent et al, 2000; Bhagwagar et al, 2002), many depressed patients display abnormal hypothalamo-pituitary-adrenal (HPA) axis function. This is manifest in a flattening of the normal diurnal rhythm of glucocorticoid levels together with an elevation of 
nadir levels (Deuschle et al, 1997; Wong et al, 2000). We have recently shown in rats, that flattening the glucocorticoid rhythm, with an elevation of the nadir, causes a desensitization of somatodendritic 5- $\mathrm{HT}_{1 \mathrm{~A}}$ autoreceptors (Leitch et al, 2003). Hence the response of $5-\mathrm{HT}_{1 \mathrm{~A}}$ receptors to flattened glucocorticoid rhythm in some part resembles their response to SSRIs. Indeed it has been suggested, that the HPA axis changes observed in depression may represent a 'natural antidepressant response' (Young, 1994). However, corticosterone has also been shown in previous studies to regulate 5-HT synthesis (Rastogi and Singhal, 1978; Miller et al, 1980; Culman et al, 1984) and may have other effects on 5-HT neurotransmission (see Chaouloff, 2000).

Given that both altered glucocorticoid rhythm and chronic SSRI treatment have been shown to alter components of 5-HT neurotransmission including $5-\mathrm{HT}_{1 \mathrm{~A}}$ autoreceptor sensitivity, it seems possible that these two factors may interact. Any such interaction may have the result of either enhancing or attenuating the ability of SSRIs to elevate forebrain 5-HT and hence may affect antidepressant efficacy. Since many depressed patients with a pre-existing flattening of their glucocorticoid rhythm will be prescribed SSRIs as a treatment for their depression, this potential interaction may be of therapeutic importance.

The present study was designed to examine whether the actions of chronic fluoxetine on 5-HT function may be modified by the concurrent presence of flattened glucocorticoid rhythm. Specifically we examined effects of the two treatments, alone and in combination, on the sensitivity of $5-\mathrm{HT}_{1 \mathrm{~A}}$ receptors controlling $5-\mathrm{HT}$ release in the frontal cortex and on extracellular levels of 5-HT in this region. In adrenally intact male rats we used slow-release corticosterone pellets in a paradigm which we have previously shown to flatten the glucocorticoid rhythm without increasing total glucocorticoid exposure (Leitch et al, 2003). We combined this corticosterone treatment (or sham surgery) with chronic once daily injection of the SSRI fluoxetine (or vehicle). Following 2 weeks' treatment, aspects of brain 5-HT neurotransmission were examined using in vivo microdialysis.

\section{METHODS}

\section{Animals}

Male Sprague-Dawley rats purchased from Bantin and Kingman, UK, were group housed with ad libitum access to food and water under controlled environmental conditions (temperature: $20^{\circ} \mathrm{C}$; humidity: $30-50 \%$ ) on a $12 \mathrm{~h}$ light/dark cycle (lights on $07.00 \mathrm{~h}$ ). Animals were allowed to acclimatize for 1 week before undergoing any procedures. This study was carried out in accordance with the UK Animals (Scientific Procedures) Act.

\section{Chronic Treatments}

Groups of rats underwent implantation of a corticosterone pellet or sham surgery and chronic injection of fluoxetine or vehicle. Rats (approx. $180 \mathrm{~g}$ ) were implanted with commercially made corticosterone pellets (Innovative Research of America, USA) designed to release $3.6 \mathrm{mg} /$ day corticosterone. Under isoflurane anesthesia, pellets were implanted subcutaneously on the right flank and the wound was sutured. Immediately following surgery, the analgesic buprenorphine $(0.05 \mathrm{mg} / \mathrm{kg}$ s.c.) was administered. Sham rats underwent the same surgical procedure but no pellet was implanted.

Following surgery, rats were housed in groups of two or three. At 2 days following surgery, chronic injections were commenced. Rats were weighed every second day and injected i.p. daily at around $13.00 \mathrm{~h}$ with of fluoxetine $(10 \mathrm{mg} / \mathrm{kg}$ i.p. in sterile water) or water vehicle $(1 \mathrm{ml} / \mathrm{kg}$ body weight).

\section{Microdialysis}

On day 13 or 14 following surgery (ie 11 or 12 days following commencement of chronic daily injections), animals underwent microdialysis under chloral hydrate anesthesia as described elsewhere (Gartside et al, 1995). Briefly, rats were anesthetized with chloral hydrate and a concentric microdialysis probe with a $3-3.5 \mathrm{~mm}$ dialysing window (Hospal membrane) was stereotaxically implanted into the right frontal cortex (stereotaxic coordinates: rostral $3.2 \mathrm{~mm}$, lateral $3.0 \mathrm{~mm}$, ventral $-4.6 \mathrm{~mm}$ from bregma and dura surface, with the incisor bar set $3.3 \mathrm{~mm}$ below the interaural line). Coordinates were adjusted for animals under $220 \mathrm{~g}$ and probe placement was verified post hoc by inspection of coronal brain sections.

The dialysis probe was continuously perfused at $2.3 \mu \mathrm{l} /$ min with artificial CSF $(140 \mathrm{mM} \mathrm{NaCl}, 3 \mathrm{mM} \mathrm{KCl}, 2.5 \mathrm{mM}$ $\mathrm{CaCl}_{2}, 1 \mathrm{mM} \mathrm{MgCl}, 1.2 \mathrm{mM} \mathrm{Na} \mathrm{HPO}_{4}, 0.27 \mathrm{mM} \mathrm{NaH} \mathrm{PO}_{4}$, $7.2 \mathrm{mM}$ glucose, $\mathrm{pH}$ 7.4). Dialysates collected over 20-min periods were injected onto a high-performance liquid chromatography (HPLC) system and separation was performed on a $100 \mathrm{~mm} \times 4.6 \mathrm{~mm} 3 \mu \mathrm{m}$ microsorb $100 \mathrm{C} 18$ HPLC column (Varian, USA) maintained at $30^{\circ} \mathrm{C}$ using a column heater (Waters). Mobile phase (127 mM NaH${ }_{2} \mathrm{PO}_{4}$, $25 \mu \mathrm{M}$ octane sulfonic acid, $0.045 \%$ EDTA, 15\% methanol, $\mathrm{pH}$ 3.9) was pumped through the system at $1.1 \mathrm{ml} / \mathrm{min}$ and 5-HT was detected using a Coulochem II (ESA Inc., USA) electrochemical detector fitted with a 5020 guard cell $(E=250 \mathrm{mV})$ and a $5014 \mathrm{~B}$ microdialysis cell $(E 1=60 \mathrm{mV}$ and $E 2=200 \mathrm{mV}$ ). The resulting peak height was measured and quantified with reference to external standards containing 50 and $500 \mathrm{fmol} 5-\mathrm{HT}$. The lower limit of detection $(2 \times$ noise $)$ of the HPLC assay for 5 -HT was around 4 fmol.

Once a stable baseline of dialysate 5 -HT was established (2-3 h after implantation), the perfusion medium was switched to one containing $10 \mu \mathrm{M}$ fluoxetine and samples collected for a further $80 \mathrm{~min}$. Rats were then injected with fluoxetine $(10 \mathrm{mg} / \mathrm{kg}$ i.p.) and dialysates were collected for a further $120 \mathrm{~min}$. Groups of two or three rats from a single treatment group were used each day. The microdialysis procedure was started at around $08.30 \mathrm{~h}$ and fluoxetine was injected around $13.00 \mathrm{~h}$.

\section{Data Analysis and Statistics}

Data shown are mean \pm SEM. Time-course dialysate 5 -HT data are presented as absolute amounts of 5-HT in the dialysate. The time-course of the response to systemic fluoxetine is also shown as change from predrug baseline (average of two predrug values). Basal 5-HT was calculated 
from the mean of the three samples before switching the perfusion medium (samples 1, 2, and 3). 5-HT levels after local perfusion of fluoxetine were calculated from the mean of samples 7 and 8 -although fluoxetine was given i.p. before sample 8 was collected, its effects did not become apparent until sample 9 and samples 7 and 8 represented the maximum levels of 5-HT attained. The area under (over) the curve for the response to systemic fluoxetine was calculated as the sum of the changes from baseline (samples 7 and 8) in the postdrug measurement period (samples 913). Statistical analysis of these data was carried out using a two-way ANOVA with fluoxetine and corticosterone as between-subject factors, with post hoc Student's $t$-tests. Significance at the $95 \%$ level and above is reported.

\section{RESULTS}

\section{General Health Indicators}

All animals appeared healthy throughout the treatment period. Although corticosterone-implanted animals lost some weight in the few days following surgery, thereafter their rate of weight gain was similar to that in the sham treatment groups. On the day of the dialysis experiment, sham/vehicle and sham/fluoxetine animals $(275.3 \pm 9.6 \mathrm{~g}$ (6) and $256.2 \pm 3.6 \mathrm{~g}$ (9), respectively) were heavier than both corticosterone/vehicle- and corticosterone/fluoxetinetreated groups $(206.0 \pm 7.6 \mathrm{~g}$ (8) and $225.6 \pm 12.5 \mathrm{~g}$ (8), respectively).

\section{Effects of Treatments on Extracellular 5-HT in the Frontal Cortex}

Basal 5-HT. Following implantation of the microdialysis probe into the frontal cortex, levels of 5-HT in the dialysates fell rapidly (data not shown) and attained relatively stable basal levels after 2-3 h (Figure 1). Basal levels of 5-HT were

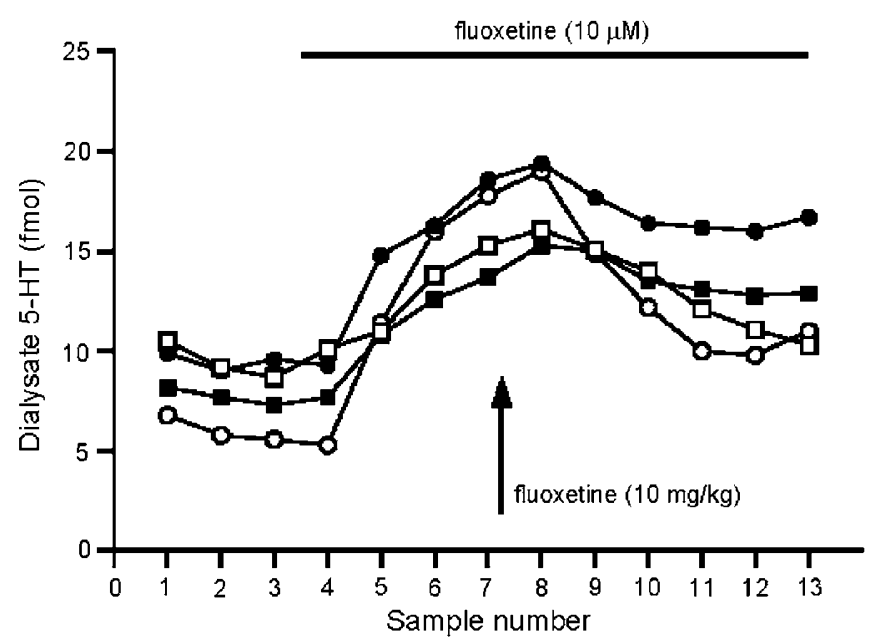

Figure I Time-course of the dialysis experiment in the four treatment groups. Dialysates were collected at 20 min intervals. Bar indicates switching of the perfusion medium to one containing $10 \mu \mathrm{M}$ fluoxetine, and arrow indicates the injection of $10 \mathrm{mg} / \mathrm{kg}$ fluoxetine (i.p.). Open circles: sham/ vehicle group $(n=6)$; closed circles: sham/fluoxetine group $(n=9)$; open squares: corticosterone/vehicle group $(n=8)$; closed squares: corticosterone/fluoxetine group $(n=8)$. Data are mean. Error bars omitted for clarity.

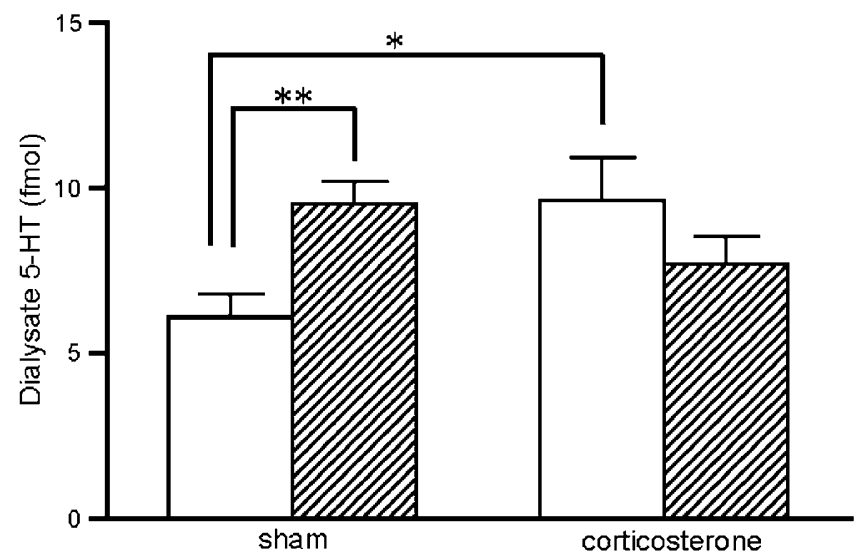

Figure 2 Basal 5-HT levels in the four treatment groups. Open columns show data from vehicle-treated animals, and shaded columns show data from fluoxetine-treated groups. Data are the mean \pm SEM calculated from samples I-3 (see Figure I). ${ }^{*} p<0.05$, ${ }^{*} p<0.0$ I, post hoc LSD test.

elevated in both the sham/fluoxetine and the corticosterone/ vehicle groups when compared to the sham/vehicle group. In the corticosterone/fluoxetine group the basal 5-HT level was intermediate between the high level in the sham/ fluoxetine and the corticosterone/vehicle groups and the lower level in the sham/vehicle group (Figure 1). The basal 5-HT levels in the four treatment groups, calculated as the mean of the last three samples before switching the perfusion medium, are presented in Figure 2. Statistical analysis of these data by two-way ANOVA revealed no significant main effect of either fluoxetine or corticosterone. However, there was a significant interaction between fluoxetine and corticosterone $\left(\mathrm{F}_{1,27}=7.7, p=0.01\right)$ and a post hoc Student's $t$-test showed that 5 -HT levels in both the sham/fluoxetine and the corticosterone/vehicle groups were significantly higher than in the sham/vehicle group.

Effect of local inhibition of 5-HT reuptake. When the perfusion medium was switched to one containing $10 \mu \mathrm{M}$ fluoxetine, levels of 5-HT in the dialysates rose over the following 80-100 min (see Figure 1). However, the new 5 -HT level attained varied between the treatment groups. Figure 3 shows the mean level in each of the four treatment groups calculated from the average of samples 7 and 8 . Local perfusion of fluoxetine raised 5-HT levels to the same levels in the sham/vehicle group and the sham/fluoxetine group. In the corticosterone/vehicle and the corticosterone/ fluoxetine groups, the levels of 5-HT also rose following local fluoxetine perfusion; however, in both cases the levels attained were lower than those in the sham surgery groups (Figure 3). Statistical analysis of these data showed that there was a significant main effect of corticosterone $\left(\mathrm{F}_{1,27}=5.2, p<0.05\right)$ but no significant main effect of fluoxetine, and no corticosterone $\times$ fluoxetine interaction.

5- $H T_{1 A}$ autoreceptor function. Following the establishment of new baseline levels of 5-HT in the presence of locally perfused fluoxetine, systemic administration of fluoxetine $(10 \mathrm{mg} / \mathrm{kg}$ i.p.) reduced dialysate 5-HT (see Figures 1 and 4$)$. In sham/vehicle-treated animals systemic fluoxetine caused a large decrease in dialysate 5-HT. However, in both sham/ fluoxetine-treated and corticosterone/vehicle-treated animals, 


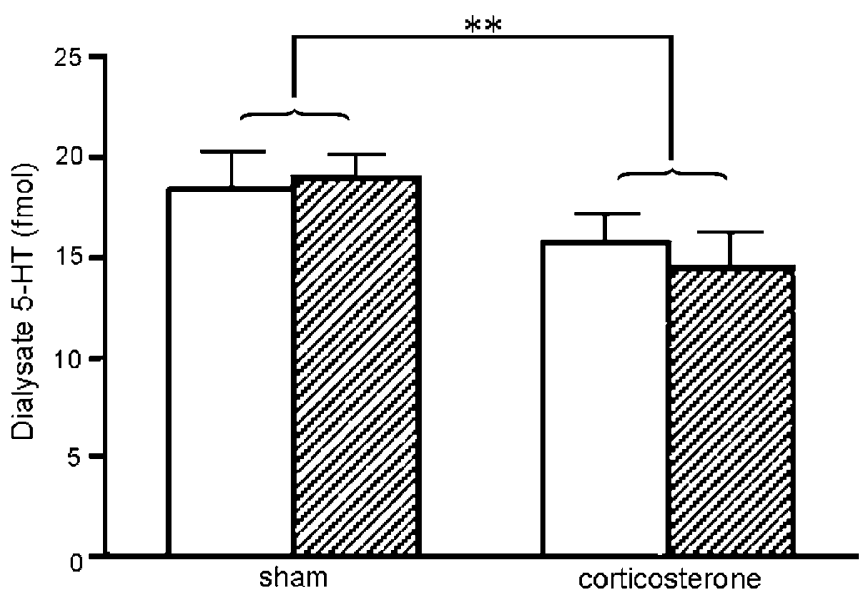

Figure $35-\mathrm{HT}$ levels in the four treatment groups after local application of fluoxetine. Open columns show data from vehicle-treated groups, and shaded columns show data from fluoxetine-treated groups. Data are the mean \pm SEM calculated from the mean of samples 7 and $8 * * p<0.01$ main effect of corticosterone treatment (ANOVA).

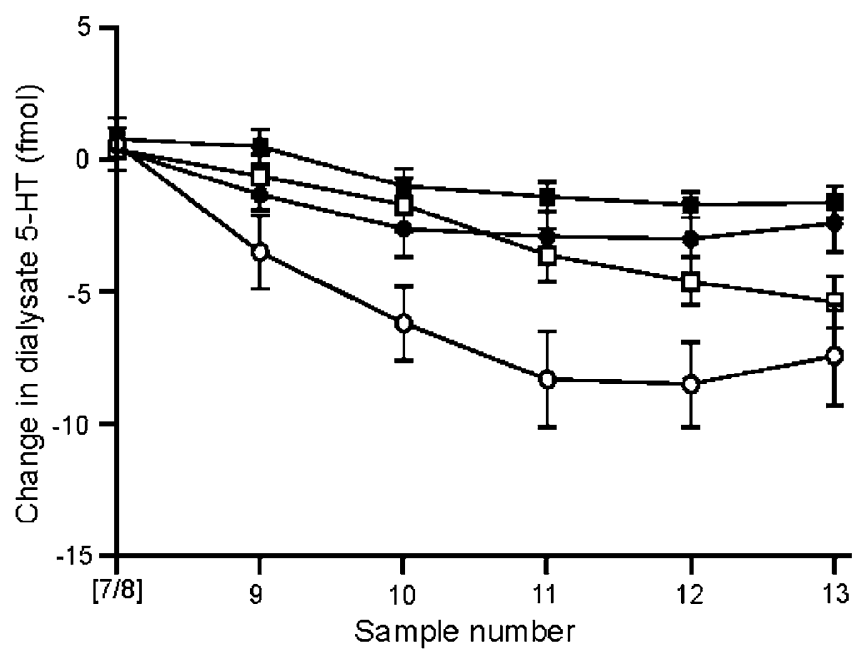

Figure 4 Time-course of the response to systemic injection of fluoxetine in the four treatment groups. Data are expressed as change from the baseline (mean of samples 7 and 8 ) and are mean \pm SEM.

this response to systemic fluoxetine was markedly attenuated compared to sham/vehicle controls. In animals that had been treated with the combination of corticosterone and fluoxetine (corticosterone/fluoxetine), the response to systemic fluoxetine was also markedly attenuated. In Figure 5 the responses to systemic fluoxetine in the four groups are shown as the area under the curve for the postdrug measurement period. Analysis of variance of the AUC data showed a significant main effect of fluoxetine $\left(\mathrm{F}_{1,27}=10.9, p=0.003\right)$ and a significant main effect of corticosterone $\left(\mathrm{F}_{1,27}=6.5, p=0.017\right)$ but no significant interaction.

\section{DISCUSSION}

In the present study we investigated the effects of chronic fluoxetine and flattened corticosterone rhythm, and their

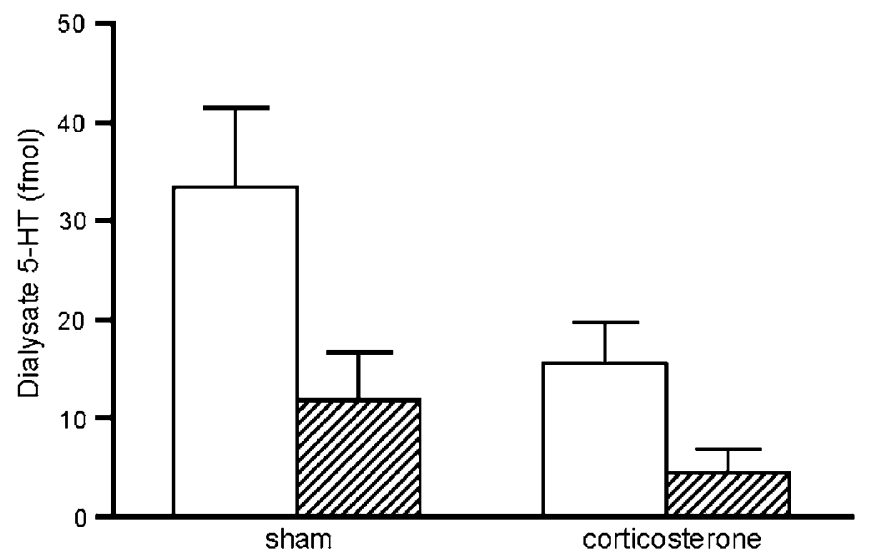

Figure 5 Response to systemic injection of fluoxetine in the four treatment groups Data are the area under the curve calculated by summing the differences from baseline (mean of samples 7 and 8 ) in the postinjection samples. For statistical analysis, see text.

possible interactions with respect to central 5-HT neurotransmission. We found that chronic fluoxetine and flattened corticosterone rhythm, both individually and in combination, markedly desensitized $5-\mathrm{HT}_{1 \mathrm{~A}}$ autoreceptors. However, the treatments differed substantially with respect to their net effects on 5-HT levels in the frontal cortex. Thus chronic fluoxetine (sham/fluoxetine) treatment elevated basal extracellular 5-HT levels (measured $21 \mathrm{~h}$ after the last dose of fluoxetine) relative to sham/vehicle controls. However, when terminal reuptake was further blocked by local perfusion of fluoxetine, 5-HT attained the same absolute level in sham/fluoxetine-treated animals as in sham/vehicle-treated controls suggesting that terminal 5-HT release was normal. In animals with flattened corticosterone rhythm (corticosterone/vehicle), basal extracellular 5-HT was also elevated compared to sham/vehicle controls but there was no elevation of basal 5-HT in the corticosterone/fluoxetine-treated group. Furthermore, following local reuptake blockade the cortical 5-HT levels attained in both corticosterone/vehicle- and corticosterone/ fluoxetine-treated groups were markedly lower than those in the sham/vehicle (and sham/fluoxetine) controls, consistent with there being decreased terminal release in corticosterone-treated animals.

\section{Chronic Fluoxetine}

Our present data showing an elevation in basal dialysate 5-HT are in accord with previous in vivo microdialysis studies in which chronic treatment with fluoxetine has been reported to increase extracellular 5-HT in the frontal cortex (Rutter et al, 1994; Invernizzi et al, 1996). Although basal 5 -HT was elevated approximately $21 \mathrm{~h}$ after the last of the chronic injections of fluoxetine, we found that local application of fluoxetine further increased dialysate $5-\mathrm{HT}$, suggesting that at this time 5 -HT reuptake in the frontal cortex is not fully inhibited. However, in the chronic fluoxetine-treated animals the level of dialysate 5-HT attained following local perfusion of fluoxetine was similar to that attained in vehicle-treated controls. These latter data, which suggest that terminal 5-HT release and hence 5-HT firing is normal(ized) in the frontal cortex of the chronic 
fluoxetine group after 12 days' treatment, are consistent with electrophysiological studies showing normalization of 5-HT firing after 2 weeks' fluoxetine treatment (Le Poul et al, 2000).

When terminal 5-HT reuptake is blocked, systemic administration of SSRIs has been shown to inhibit 5-HT release via activation of $5-\mathrm{HT}_{1 \mathrm{~A}}$ receptors (Hjorth and Auerbach, 1996). Here we used this decrease in dialysate $5-\mathrm{HT}$ as an index of $5-\mathrm{HT}_{1 \mathrm{~A}}$ receptor sensitivity. We observed that in the chronic fluoxetine-treated (sham/ fluoxetine) animals, the magnitude of the inhibitory response to systemic fluoxetine was markedly diminished compared to that seen in the sham/vehicle-treated controls. This finding is consistent with chronic fluoxetine treatment having induced a functional desensitization of $5-\mathrm{HT}_{1 \mathrm{~A}}$ autoreceptors and again is in line with previous reports (Le Poul et al, 1995; Invernizzi et al, 1996).

\section{Flattened Glucocorticoid Rhythm}

Like chronic fluoxetine, chronic flattening of the glucocorticoid rhythm (by clamping levels at a point midway between the normal nadir and zenith (Leitch et al, 2003)) resulted in an increase in basal dialysate 5-HT. Indeed the levels of 5-HT in the corticosterone/vehicle group were very similar to those in the sham/fluoxetine group $21 \mathrm{~h}$ after the last injection. However, when terminal 5-HT reuptake was blocked by local perfusion of fluoxetine, the level of dialysate 5-HT attained in the corticosterone/vehicle-treated animals was significantly lower than that in either the sham/ fluoxetine or the sham/vehicle group. Finally, corticosterone-treated animals showed evidence of a $5-\mathrm{HT}_{1 \mathrm{~A}}$ receptor desensitization, which was of the same degree of magnitude as that in chronic fluoxetine-treated animals. This is fully consistent with our own recent data in which we found that the 8-OHDPAT-induced inhibition of 5-HT release was markedly reduced in animals treated with this regime of corticosterone (Leitch et al, 2003).

The mechanism underlying the effects of flattening the glucocorticoid rhythm on basal 5-HT is not clear, but would be consistent with either a decrease in reuptake and/or an increase in terminal 5-HT release. There are few data available on the effects of glucocorticoids on the 5-HT transporter, but what evidence is available suggests that flattened glucocorticoid rhythm is unlikely to decrease 5-HT reuptake (Kulikov et al, 1997; Fernandez et al, 2001). An increase in 5-HT release is possible; however it is unlikely that this is secondary to the $5-\mathrm{HT}_{1 \mathrm{~A}}$ receptor desensitization as pharmacological blockade of these receptors with WAY100635 has been shown to have no effect on 5-HT levels in frontal cortex dialysates (Gartside et al, 1995; Sharp et al, 1997; Invernizzi et al, 1996). A more likely mechanism underlying increased 5-HT release would be an increase in the activity of tryptophan hydroxylase, an enzyme that has previously been shown to be increased by high corticosterone and stress (Rastogi and Singhal, 1978; Culman et al, 1984). Whatever the mechanism of this increase in basal 5-HT, this effect of corticosterone is difficult to reconcile with the reduction in absolute 5-HT levels when terminal 5-HT reuptake was blocked. One possibility is that the corticosterone treatment increases 5-HT synthesis and release but, at the same time, increases the sensitivity of terminal $5-\mathrm{HT}_{1 \mathrm{~B}}$ autoreceptors. Evidence suggests that the negative influence of $5-\mathrm{HT}_{1 \mathrm{~B}}$ autoreceptors on 5-HT release is only manifest when synaptic levels are relatively high (Sharp et al, 1997; Roberts et al, 1999). Hence, in corticosterone-treated animals increased $5-\mathrm{HT}_{1 \mathrm{~B}}$ sensitivity could limit release when terminal reuptake is blocked while having no effect on (lower) basal levels. To our knowledge, the effects of glucocorticoids on the function of $5-\mathrm{HT}_{1 \mathrm{~B}}$ terminal autoreceptors (as opposed to postsynaptic $5-\mathrm{HT}_{1 \mathrm{~B}}$ receptors) has not been reported. Although corticosteroids have been shown to be without influence on $5-\mathrm{HT}_{1 \mathrm{~B}}$ receptor mRNA expression in the DRN (Neumaier et al, 2000 ), changes in $5-\mathrm{HT}_{1 \mathrm{~B}}$ receptor function downstream of transcription are possible.

\section{Interaction between Flattened Glucocorticoid Rhythm and Chronic Fluoxetine}

A key part of the present study was to examine the interactions between flattened corticosterone rhythm and chronic fluoxetine. We found that the combination of flattened glucocorticoid rhythm and chronic fluoxetine (corticosterone/fluoxetine) caused desensitization of $5-\mathrm{HT}_{1 \mathrm{~A}}$ autoreceptors. Indeed, the combined treatment was, if anything, slightly more effective than either treatment alone. Although we found no statistical evidence for an interaction between the two treatments, this is most likely to be due to the magnitude of the desensitization to either treatment alone being near maximal and does not necessarily suggest that SSRIs and flattened corticosterone rhythm desensitize $5-\mathrm{HT}_{1 \mathrm{~A}}$ receptors via the same molecular mechanism. In this respect, it is perhaps of note that Le Poul et al (1997) showed that the mechanism by which fluoxetine causes desensitization of $5-\mathrm{HT}_{1 \mathrm{~A}}$ receptors is independent of its ability to cause acute corticosterone release.

In examining the interaction between flattened corticosterone rhythm and chronic fluoxetine, our most striking finding was that a concurrent flattened glucocorticoid rhythm decreased the ability of chronic fluoxetine to elevate forebrain $5-\mathrm{HT}$. This was evidenced by the fact that $5-\mathrm{HT}$ levels in the corticosterone/fluoxetine group were lower than those in the sham/fluoxetine group both when 5-HT reuptake was only partially blocked $(21 \mathrm{~h}$ after the last fluoxetine injection) and when it was maximally blocked (after local perfusion of fluoxetine). It is unclear how corticosterone brings about this effect although, as discussed above, flattened glucocorticoid rhythm may have effects on 5-HT synthesis and/or 5-HT autoreceptors. Whatever the precise molecular effects of glucocorticoids, it is apparent that in animals with flattened glucocorticoid rhythm the ability of chronic fluoxetine to elevate synaptic 5 -HT levels is attenuated even though $5-\mathrm{HT}_{1 \mathrm{~A}}$ receptors are effectively desensitized.

\section{Conclusions}

An elevation in synaptic 5-HT levels in the forebrain is proposed to underlie the antidepressant response to SSRIs (see Blier, 2001). Interestingly, it was recently reported that upwards of $75 \%$ transporters are occupied at clinically effective doses of SSRIs (Meyer et al, 2001). At baseline (ie 
$21 \mathrm{~h}$ after the last fluoxetine injection) it seems probable that reuptake blockade was only partial; however, blockade was probably close to maximal following local perfusion of fluoxetine. Hence the levels of 5-HT attained here following local reuptake blockade may be the most clinically relevant. Corticosterone alone caused an increase in basal 5-HT (which might have some antidepressant effect); however, levels remain much lower than those that may be achieved by (total) reuptake blockade. Importantly in animals with flattened glucocorticoid rhythm, the maximum 5-HT levels achieved following reuptake blockade were significantly reduced. The desensitization of $5-\mathrm{HT}_{1 \mathrm{~A}}$ autoreceptors may be crucial in allowing the effect of SSRIs on terminal 5-HT to be manifest; however, the present study provides evidence that concurrent flattened glucocorticoid rhythm compromises the ability of an SSRI to elevate forebrain $5-\mathrm{HT}$, even in the presence of desensitized $5-\mathrm{HT}_{1 \mathrm{~A}}$ autoreceptors.

Flattened glucocorticoid rhythm with raised nadir is seen in a significant proportion of depressed patients as well as in the elderly (Wong et al, 2000; Ferrari et al, 2001), and the present data suggest that in these individuals the antidepressant efficacy of SSRIs may be severely compromised. Indeed our findings may explain the recent observation of limited efficacy of SSRIs in patients with abnormal HPA axis function (Young et al, 2002). Tricyclic antidepressants unlike SSRIs are reported to alter glucocorticoid receptor function (Pepin et al, 1989). Hence TCAs may be able to normalize glucocorticoid rhythm, a property that may confer greater efficacy in depressed patients with glucocorticoid abnormalities. Further investigations of the interplay between glucocorticoids and 5-HT function in relation to antidepressants are clearly warranted.

\section{ACKNOWLEDGEMENTS}

This work was supported by the Stanley Medical Research Foundation.

\section{REFERENCES}

Artigas F, Celada P, Laruelle M, Adell A (2001). How does pindolol improve antidepressant action? Trends Pharmacol Sci 22: 224228.

Bhagwagar Z, Whale R, Cowen PJ (2002). State and trait abnormalities in serotonin function in major depression. $\mathrm{Br} J$ Psychiatry 180: 24-28.

Blier P (2001). Pharmacology of rapid-onset antidepressant treatment strategies. J Clin Psychiatry 62(Suppl 15): 12-17.

Blier P, de Montigny C, Chaput Y (1987). Modifications of the serotonin system by antidepressant treatments: implications for the therapeutic response in major depression. J Clin Psychopharmacol 7(Suppl 6): 24S-35S.

Chaouloff F (2000). Serotonin, stress and corticoids. J Psychopharmacol 14: 139-151.

Culman J, Kiss A, Kvetnansky R (1984). Serotonin and tryptophan hydroxylase in isolated hypothalamic and brain stem nuclei of rats exposed to acute and repeated immobilization stress. Exp Clin Endocrinol 83: 28-36.

Davidson C, Stamford JA (1998). Contrasting effects of chronic paroxetine on 5- $\mathrm{HT}_{1 \mathrm{~A}}$ control of dorsal raphe cell firing and 5HT release. Neuroreport 9: 2535-2538.
Dawson LA, Nguyen HQ, Smith DI, Schechter LE (2000). Effects of chronic fluoxetine treatment in the presence and absence of (+/-)pindolol: a microdialysis study. Br J Pharmacol 130: 797-804.

de Montigny C, Chaput Y, Blier P (1990). Modification of serotonergic neuron properties by long-term treatment with serotonin reuptake blockers. J Clin Psychiatry 51(Suppl B): 4-8.

Deuschle M, Schweiger U, Weber B, Gotthardt U, Korner A, Schmider J et al (1997). Diurnal activity and pulsatility of the hypothalamus-pituitary-adrenal system in male depressed patients and healthy controls. J Clin Endocrinol Metab 82: 234-238.

Drevets WC, Frank E, Price JC, Kupfer DJ, Greer PJ, Mathis C (2000). Serotonin type-1A receptor imaging in depression. $\mathrm{Nucl}$ Med Biol 27: 499-507.

Fernandez F, Coomans V, Mormede P, Chaouloff F (2001). Effects of corticosterone ingestion on hippocampal $\left[{ }^{3} \mathrm{H}\right]$ serotonin reuptake in inbred rat strains. Endocr Regul 35: 119-126.

Ferrari E, Cravello L, Muzzoni B, Casarotti D, Paltro M, Solerte SB et al (2001). Age-related changes of the hypothalamic-pituitaryadrenal axis: pathophysiological correlates. Eur J Endocrinol 144: 319-329.

Gardier AM, Malagie I, Trillat AC, Jacquot C, Artigas F (1996). Role of $5-\mathrm{HT}_{1 \mathrm{~A}}$ autoreceptors in the mechanism of action of serotoninergic antidepressant drugs: recent findings from in vivo microdialysis studies. Fundam Clin Pharmacol 10: 16-27.

Gartside SE, Umbers V, Hajos M, Sharp T (1995). Interaction between a selective $5-\mathrm{HT}_{1 \mathrm{~A}}$ receptor antagonist and an SSRI in vivo: effects on 5-HT cell firing and extracellular 5-HT. $\mathrm{Br} J$ Pharmacol 115: 1064-1070.

Hjorth S, Auerbach SB (1996). 5- $\mathrm{HT}_{1 \mathrm{~A}}$ autoreceptors and the mode of action of selective serotonin reuptake inhibitors (SSRI). Behav Brain Res 73: 281-283.

Invernizzi R, Bramante $M$, Samanin R (1996). Role of $5-\mathrm{HT}_{1 \mathrm{~A}}$ receptors in the effects of acute chronic fluoxetine on extracellular serotonin in the frontal cortex. Pharmacol Biochem Behav 54: 143-147.

Kulikov A, Mormede P, Chaouloff F (1997). Effects of adrenalectomy and corticosterone replacement on diurnal $\left[{ }^{3} \mathrm{H}\right]$ citalopram binding in rat midbrain. Neurosci Lett 222: 127-131.

Laaris N, Le Poul E, Hamon M, Lanfumey L (1997). Stress-induced alterations of somatodendritic $5-\mathrm{HT}_{1 \mathrm{~A}}$ autoreceptor sensitivity in the rat dorsal raphe nucleus - in vitro electrophysiological evidence. Fundam Clin Pharmacol 11: 206-214.

Leitch MM, Ingram $\mathrm{CD}$, Young $\mathrm{AH}$, McQuade $\mathrm{R}$, Gartside SE (2003). Flattening the corticosterone rhythm attenuates $5-\mathrm{HT}_{1 \mathrm{~A}}$ autoreceptor function in the rat: relevance for depression. Neuropsychopharmacology 28: 119-125.

Le Poul E, Boni C, Hanoun N, Laporte AM, Laaris N, Chauveau J et al (2000). Differential adaptation of brain 5- $\mathrm{HT}_{1 \mathrm{~A}}$ and $5-\mathrm{HT}_{1 \mathrm{~B}}$ receptors and 5-HT transporter in rats treated chronically with fluoxetine. Neuropharmacology 39: 110-122.

Le Poul E, Laaris N, Doucet E, Laporte AM, Hamon M, Lanfumey L (1995). Early desensitization of somato-dendritic 5- $\mathrm{HT}_{1 \mathrm{~A}}$ autoreceptors in rats treated with fluoxetine or paroxetine. Naunyn Schmiedebergs Arch Pharmacol 352: 141-148.

Le Poul E, Laaris N, Hamon M, Lanfumey L (1997). Fluoxetineinduced desensitization of somatodendritic $5-\mathrm{HT}_{1 \mathrm{~A}}$ autoreceptors is independent of glucocorticoid(s). Synapse 27: 303-312.

Meyer JH, Wilson AA, Ginovart N, Goulding V, Hussey D, Hood K et al (2001). Occupancy of serotonin transporters by paroxetine and citalopram during treatment of depression: a $\left[\left({ }^{11}\right)\right.$ C $]$ DASB PET imaging study. Am J Psychiatry 158: 1843-1849.

Miller M, Hasson R, Morgane PJ, Resnick O (1980). Adrenalectomy: its effects on systemic tryptophan metabolism in normal and protein malnourished rats. Brain Res Bull 5: 451-459.

Neumaier JF, Sexton TJ, Hamblin MW, Beck SG (2000). Corticosteroids regulate $5-\mathrm{HT}_{1 \mathrm{~A}}$ but not $5-\mathrm{HT}_{1 \mathrm{~B}}$ receptor mRNA in rat hippocampus. Mol Brain Res 82: 65-73. 
Pepin MC, Beaulieu S, Barden N (1989). Antidepressants regulate glucocorticoid receptor messenger RNA concentrations in primary neuronal cultures. Brain Res Mol Brain Res 6: 77-83.

Rastogi RB, Singhal RL (1978). Adrenocorticoids control 5hydroxytryptamine metabolism in rat brain. J Neural Transm 42: 63-71.

Roberts C, Boyd DF, Middlemiss DN, Routledge C (1999). Enhancement of 5- $\mathrm{HT}_{1 \mathrm{~B}}$ and $5-\mathrm{HT}_{1 \mathrm{D}}$ receptor antagonist effects on extracellular 5-HT levels in the guinea-pig brain following concurrent $5-\mathrm{HT}_{1 \mathrm{~A}}$ or 5 -HT re-uptake site blockade. Neuropharmacology 38: 1409-1419.

Rutter JJ, Gundlah C, Auerbach SB (1994). Increase in extracellular serotonin produced by uptake inhibitors is enhanced after chronic treatment with fluoxetine. Neurosci Lett 171: 183-186.

Sargent PA, Kjaer KH, Bench CJ, Rabiner EA, Messa C, Meyer J et al (2000). Brain serotonin ${ }_{1 \mathrm{~A}}$ receptor binding measured by positron emission tomography with $\left[{ }^{11} \mathrm{C}\right]$ WAY-100635: effects of depression and antidepressant treatment. Arch Gen Psychiatry 57: $174-180$.
Sharp T, Umbers V, Gartside SE (1997). Effect of a selective 5-HT reuptake inhibitor in combination with $5-\mathrm{HT}_{1 \mathrm{~A}}$ and $5-\mathrm{HT}_{1 \mathrm{~B}}$ receptor antagonists on extracellular 5-HT in rat frontal cortex in vivo. Br J Pharmacol 121: 941-946.

Wong ML, Kling MA, Munson PJ, Listwak S, Licinio J, Prolo P et al (2000). Pronounced and sustained central hypernoradrenergic function in major depression with melancholic features: relation to hypercortisolism and corticotropin-releasing hormone. Proc Natl Acad Sci USA 97: 325-330.

Young AH (1994). Glucocorticoids, serotonin and mood. $\mathrm{Br} J$ Psychiatry 165: 271-272.

Young AH, Goodwin GM, Dick H, Fink G (1994). Effects of glucocorticoids on $5-\mathrm{HT}_{1 \mathrm{~A}}$ presynaptic function in the mouse. Psychopharmacology (Berl) 114: 360-364.

Young EA, Altemus M, Lopez JF, Kocsis JH, Schatzberg AF, de Battista C et al (2002). Relationship between HPA axis activation and the response to fluoxetine. Am J Psychiatry, submitted 2002 . 